\title{
Trends in the Internet of Things (IoT) and Influence on the Industries' Progress
}

\author{
V. Z. LORESTANI \\ PhD Student of Ihrig Károly Doctoral School, University of Debrecen, Hungary, vahid.zeynvand@econ.unideb.hu
}

\begin{abstract}
This research aims to investigate the critical role of the Internet of Things in the future of industries' progress. For this purpose, a survey of 250 top managers across 13 industries has conducted. The objective was to find their view of point about what short and mega trends, in which sector will have the most considerable influence in the five years as well as 30 years ahead. Moreover, various technologies are also identified that will have the most importance in the future according to the majority of the respondents, such as Internet of things, Automation and Artificial Intelligence, and, on the other hand, the segments that capital expenditure is currently being directed towards, such as Energy Efficiency and Personalisation of Services.
\end{abstract}

\section{Introduction}

The IoT concept defined by a member of the 'Radio Frequency Identification development community' in 1999. After several years, now it is more critical to the real-world primarily due to the significant level of utilizing devices, universal relationships, so on. Internet of things (IoT) is a network of physical objects. The internet is not only a network of computers, but it has evolved into a network of the device of all type and sizes. For instance, vehicles, smartphones, home appliances, toys, cameras, medical instruments and industrial systems, animals, people, buildings, all connected information that based on stipulated protocols in order to achieve smart reorganizations, positioning, tracing, safe \& control. Even personal, real-time, online monitoring, online upgrade, process control \& administration, etc. [1]. Thus, it is evident that nowadays IoT deal with all aspects of human beings life that's why it has a significant influence on the level of welfare as well.

There are three major categories for the Internet of Things [2]:

1. 'People to people', we are living in a 'Global village'. Distances are not significant issues now. People can contact together by one click on an application in one second quickly.

2. 'People to machine things', to find correct references is the most crucial concern for a researcher. Nowadays, 'engine motors' on the base on IoT, facilitated to recognize and find the references for all the researcher in some minutes.

3. Things (machine to things) machine', currently, when we go to the factories, a lot of machines or things are faced which Interacting through the internet. Some of them work as the brain of the factory and order to robots or other machines to produce products [3]. 
Successful adaptation involves tailoring to the improvement of technology to change resources and meet the increasing needs of developing countries [4]. These countries can simply take the appropriate and necessary technologies available from off the shelf and apply them around the rest of the world [5]. The empirical findings also suggest that the positive effect of the latest technological adoptions is robust in the case of emerging markets [6], manufacturing [7] and other knowledge and technology intensive industries [8], in the role of the technology transfer and diffusion [9], [10].

The aim of this analysis is to determine the influence of the Internet on Things in the case of industries in the forthcoming decades. This study focuses directly on how the access to and usage of the IoT, and the capital expenditure (capex) investments of new technologies are related to the industrial tendencies. The rest of this paper is divided into additional sections. The next section briefly describes the brief vison of this research topic. Section two and three describes the industrial trends in Internet of Things and the role of capex investments. Finally, the paper ends with some conclusions and implications.

\section{Internet of Things Vision}

The Internet of Things (IoT) is transforming businesses and peoples' lives and will continue to ignite innovations in the future. It is expected to progress tens of billions of connected devices globally over the next decade that will generate multi-trillion dollars of economic value across many markets forming the foundation of an interconnected world - or the Internet of Everything [11]. In order to understand the critical role of IoT in future, it is worth to highlight the tragedy happened for Nokia Company in last years. Nokia was the market leader of mobile devices between 1991 to 2010. However, it bankrupted in 2015.

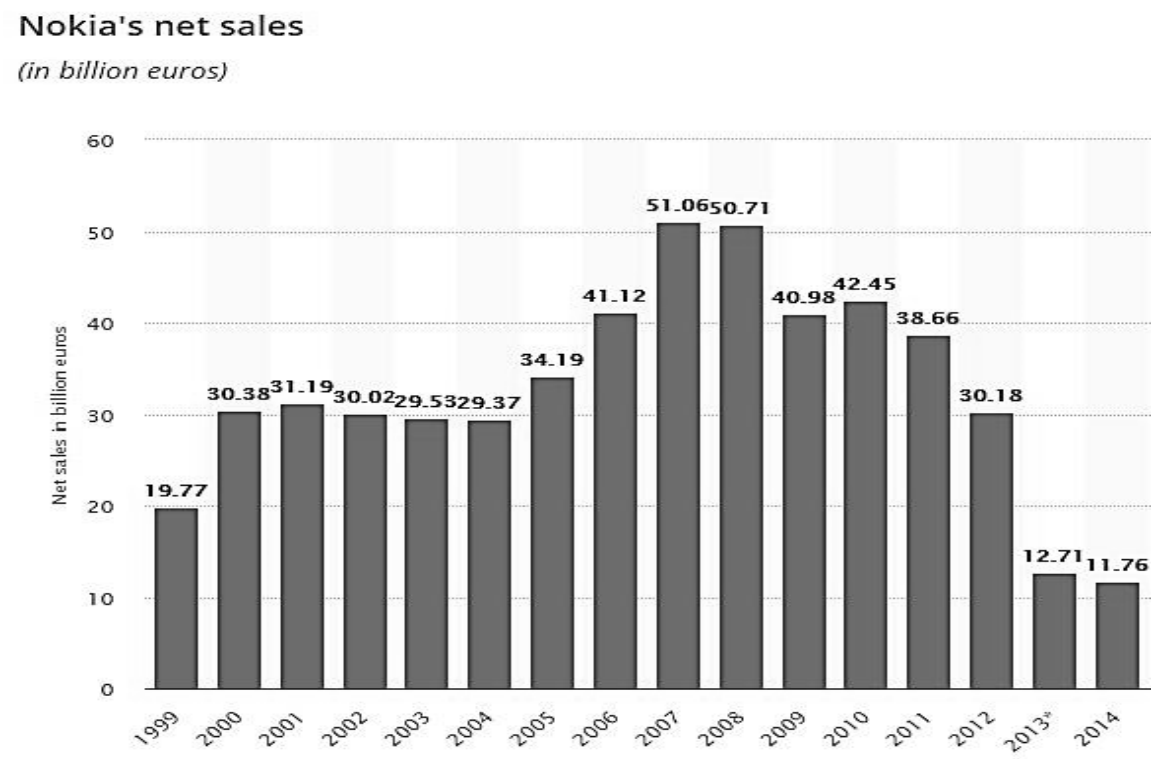

Figure 1. Nokia's Net Sales between 1999 and 2014. Source [11].

Nokia CEO cried during his last speech and said: 'We did not make any mistake. However, somehow, we lost!'. The main reason for the Nokia tragedy was the decision-makers in this famous company did not 
take care of what was happening in the market. They did not pay attention to the competitors' vision about trends of IoT and its influence on Smartphones. Internet of Things (IoT) is a pattern that considers a multiplicity of things/objects by wireless or wired connections to cooperate with other machines to create new valuable things. IoT is a revolution of the Internet. Objects archive to information aggregated by other data or machines, or they can be parts of multiplex things.

\section{Trends in Internet of Things}

According to the above facts, all people must know that what will be the trend of IoT soon. Internet of things and automation will be the major performers during the next half-century, based on an Industry Survey [12]. In this empirical research, two hundred fifty top managers from 13 sectors participated in this research (Figure 2). The research aims to find their vision about the tendency in the industry will have the most considerable influence in the next five as well as 30 years.

IoT has the most considerable influence, and 3D printing is the lowest one based on the respondents.

During the next five years, $72 \%$ agree that Internet of thing will be the most performer in their sector, Automation at $64 \%$. During the next 30 years, $80 \%$ agree that Internet of thing will be the most performer in their sector, Automation at $75 \%$ (Figure 3).

Respondents from agribusiness and Autos have the lowest amount of response to mention that there is a strong influence in automation and Robotics, whereas Consumer and Retail had the highest percentage nineteen per cent of seeing No Impact on their industry by Automation and Robotics in the next five years (Figure 4).

In thirty years, one hundred per cent of the respondents of Utilities space industry accept Automation \& Robotics the most substantial influence. Also, 78\% of Construction industry respondents accept that Automation \& Robotics will have a significant influence in the sector (Figure 5).

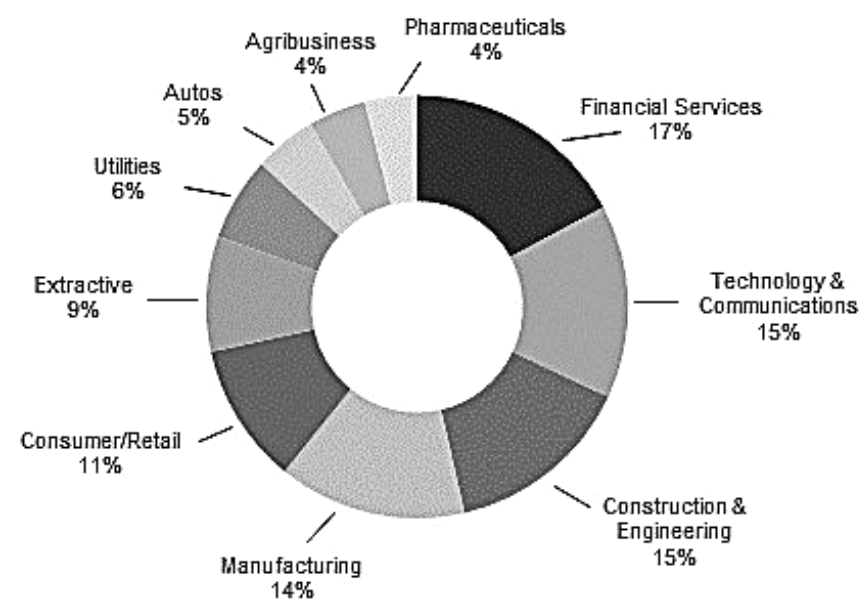

Figure 2. Distribution of Survey Participants based on industries 


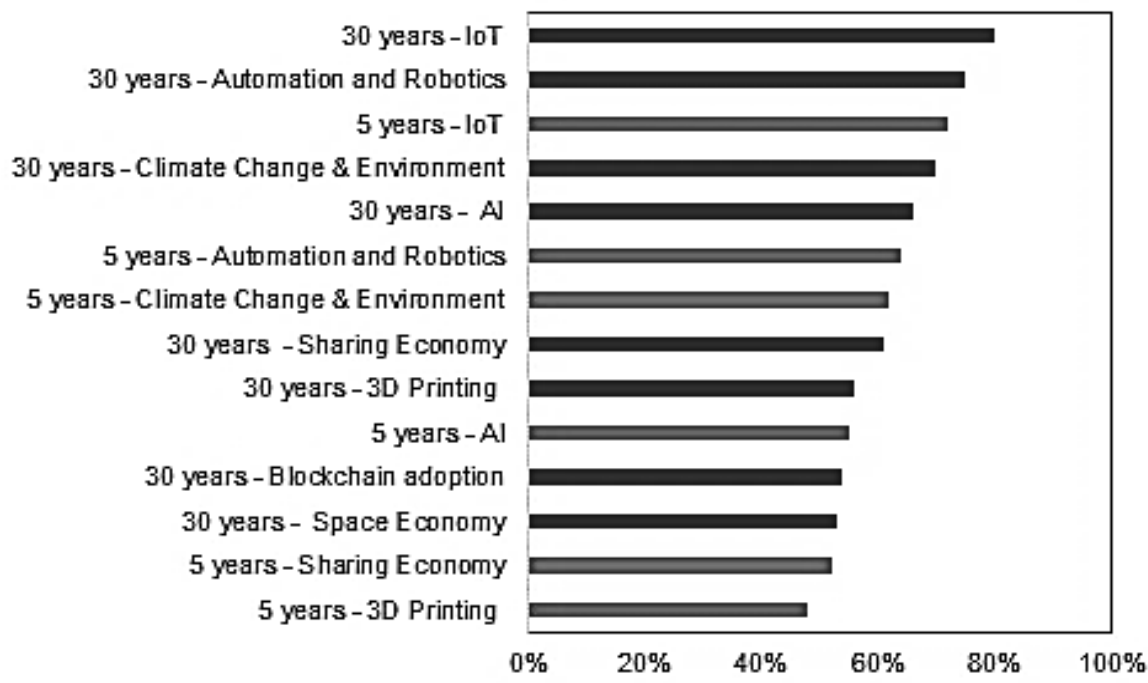

Figure 3. The per cent of "High Impact" of performer on the industry in the next 5 and 30 years, by technology.

Note: In the next five years as well as thirty years, rate the performer in your sector in following technologies.

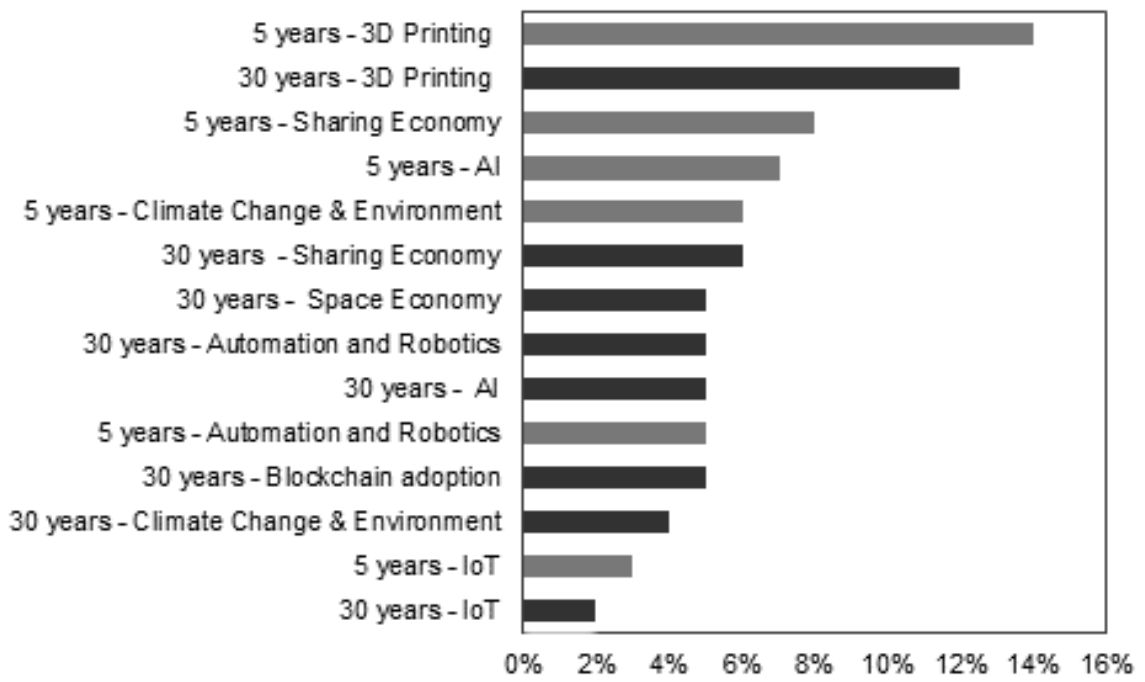

Figure 4. The per cent of "No Impact" of performer on the industry in the next 5 and 30 years, by technology.

Note: In the next 5 years as well as 30 years, rate the performer in your sector in following technologies items. 


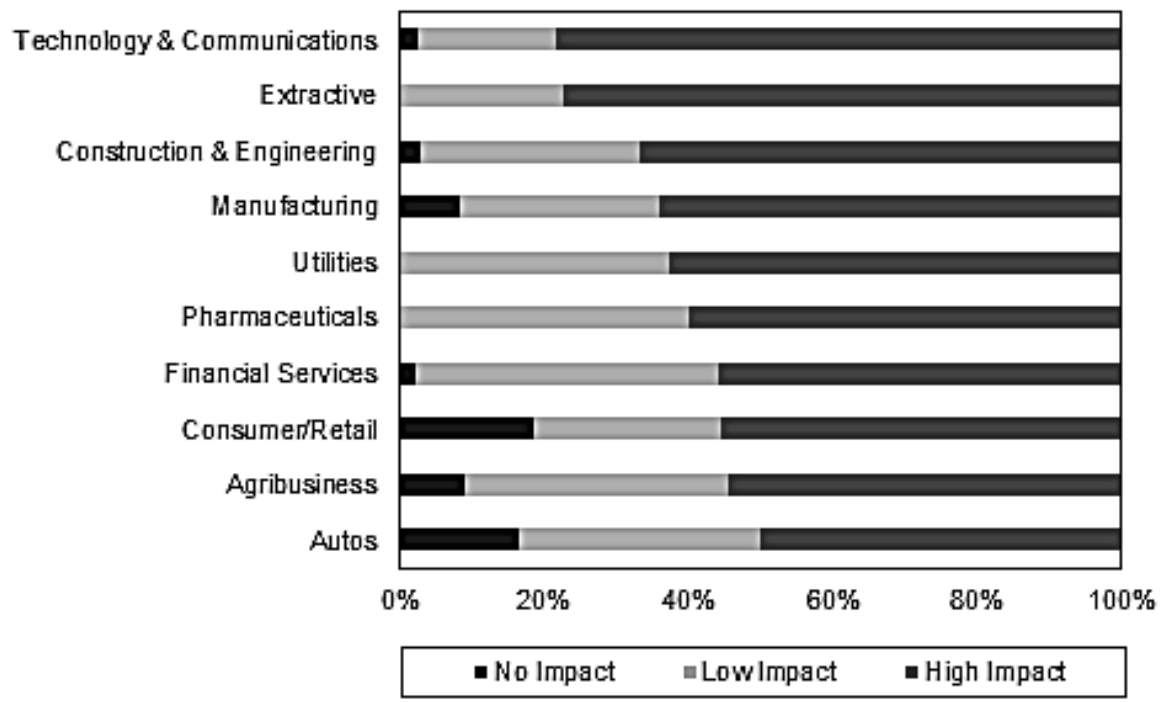

Figure 5. The percentage of respondents on the impact of 'Automation \& Robotics' on their sector over 5 years. Note: In the next 5 years, rate the potential disruption to your industry's current business model.

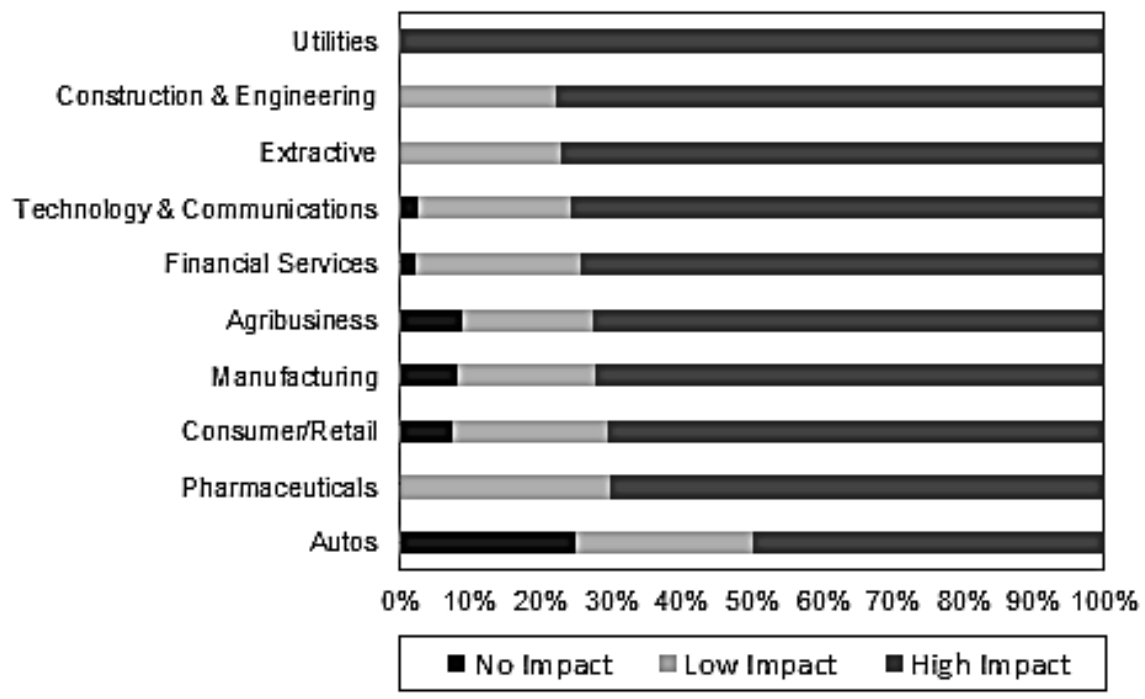

Figure 6. The percentage of respondents on the impact of 'Automation \& Robotics' on their sector over 30 years.

Note: In the next 30 years, rate the potential disruption to your industry's current business model from Automation \& Robotics.

Most of the respondents in Technology \& Communications, Pharmaceuticals, and Construction industries believe that the Internet of Things has the most substantial influence on their sectors in the next five years. However, respondents in the Agribusiness and Autos have a few amounts of respondents that the Internet of things has a High influence on their industries in the next five years (Figure 6).

In the period of next thirty years, Ninety per cent of extractive industries and eighty-six per cent of Financial Services accept that internet of things will have a significant influence in their industries, up 
from seventy-three per cent to seventy per cent and in the coming five years. The respondents of autos, as well as agribusiness believe that internet of thing has a major influence in the next five and 30 years (Figure 7 and 8).

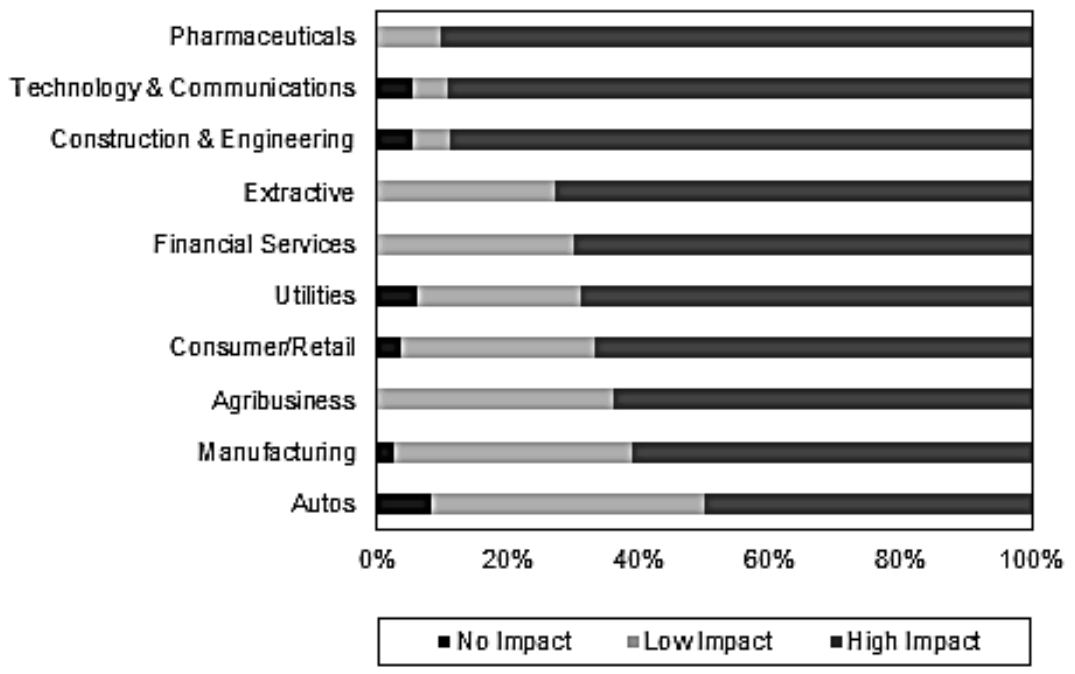

Figure 7. The percentage of respondents on the impact of 'IoT' on their sector over 5 years. Note: In the next 5 years, rate the potential disruption to your industry's current business model from IoT.

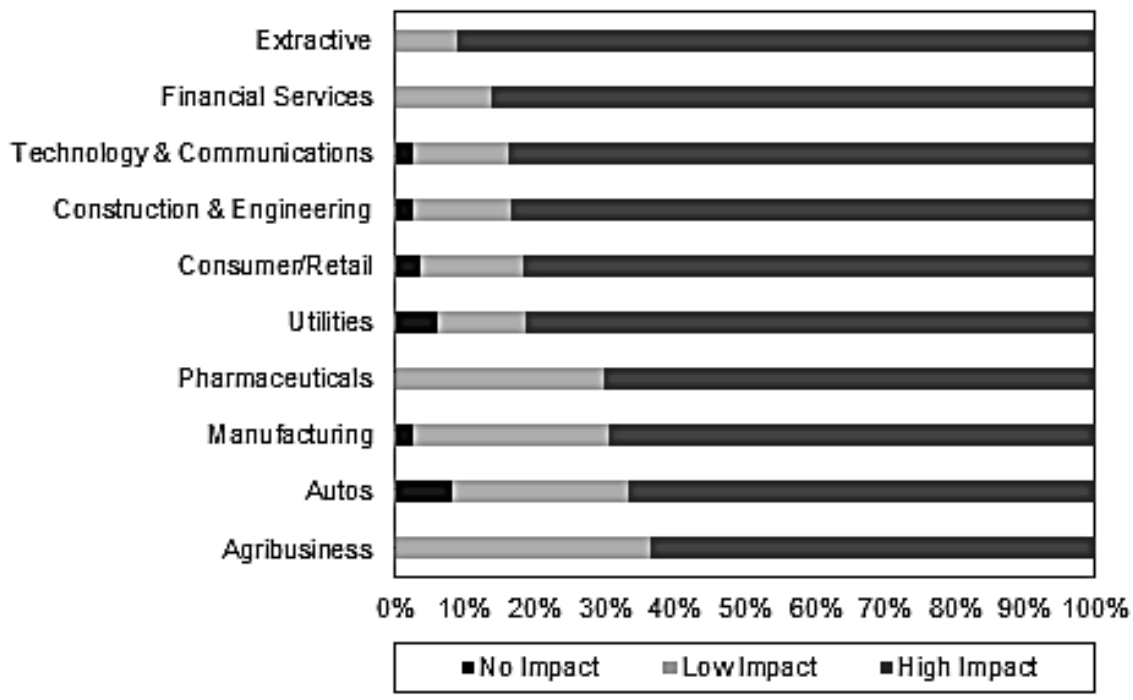

Figure 8. The percentage of respondents on the impact of 'IoT' on their sector over 30 years.

Note: In the next 30 years, rate the potential disruption to your industry's current business model from IoT. 


\section{The Role of Capital Expenditure}

The new investment is the lifeblood of a firm. Typically new investment arises through either capital expenditure or business acquisitions. Much of the research concerning acquisitions have focused on the change of control transactions such as mergers and takeovers [13]. Corporate capital expenditures have received less attention. The few studies in the area that examine the market reaction to capital expenditure announcements all report a significantly positive price response.

Based on the respondents [12], most of the capital expenditure of these firms now is targeted to Energy Efficiency (seventy-two per cent) by Personalisation of Services (sixty-three per cent). Unexpectedly, and indifference to the responses in the questions earlier to be major performers, Automation \& Robotics and Internet of things are in the latest two places of the respondents. It approves that there is an absence of investing; on the other hand, there is no regulation considering at this important item through M\&A, considerable cooperation. This is also important and should be considered by enterprises to look about their previous experiences by others before implementing more expenditures in new technologies such as the Internet of Things.

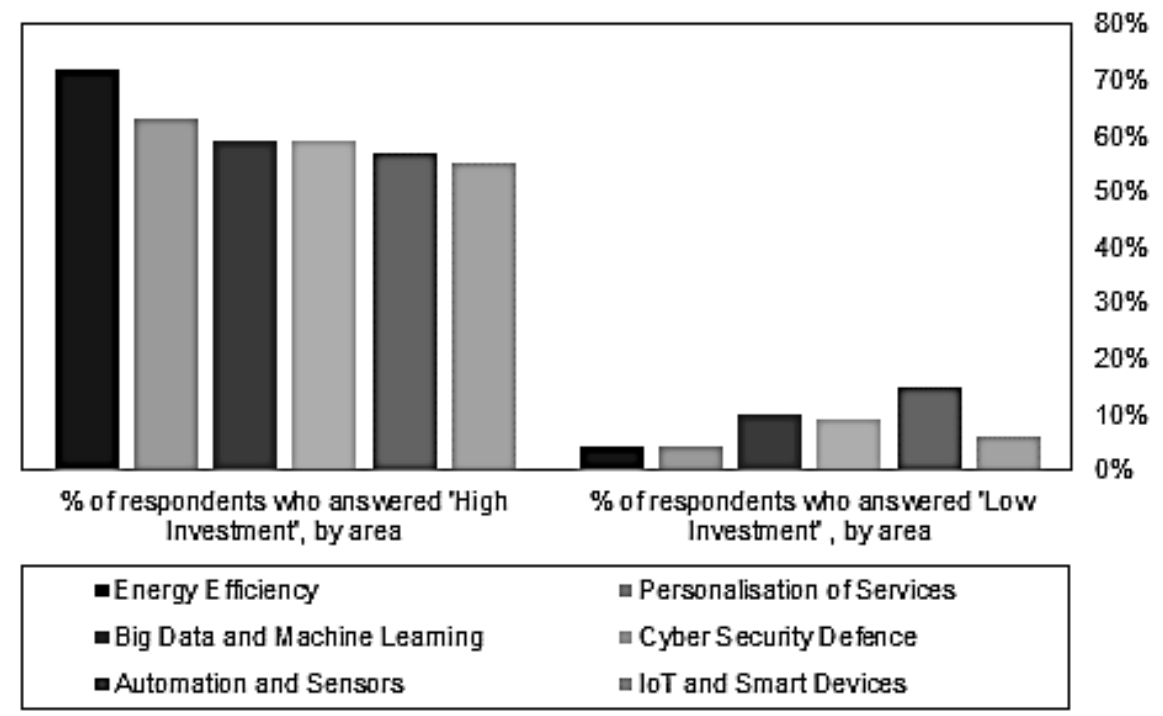

Figure 9. The percentage of respondents on the areas of High and Low investment in their company

Note: In which of these areas is your company investing in most heavily right now

The Automation industry and Utilities have big differences in the temporary outlay provisions and continuing strategic concerns [14]. Although managers in these sectors imagine internet of things and smartphones to have a major influence on their approach in the next thirty years, their capital expenditure is now concentrated on environment and energy efficiency.

This difference comes from the Auto and Utilities industries adoption and expanding of state-of-the-art technologies such as the Internet of things and Master Data will implement through considerable cooperation and by a focus on the venture (Figure 9). The first part, maybe unexpectedly, happened when respondents generally are not agreed that capital expenditure being complete as an 
overpoweringly high area of focus is Cybersecurity. Cybersecurity has become a matter of global interest and importance. Already more than 50 nations have officially term to protect a computer system (as on the Internet) against published some form of strategy document outlining their official stance on cyberspace, cybercrime, and/or cybersecurity.

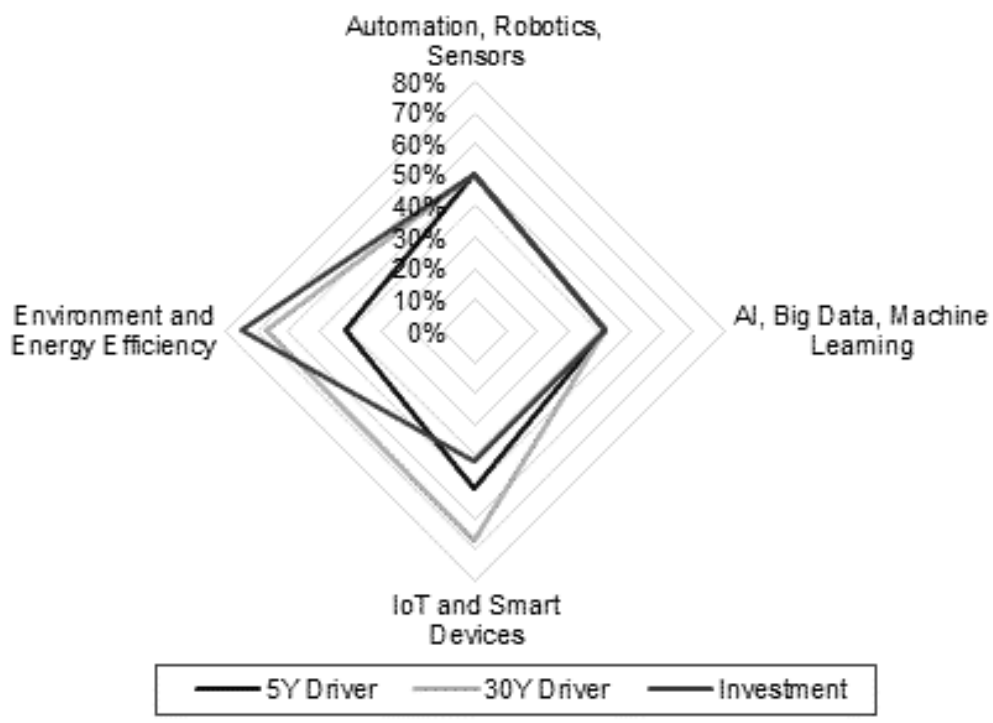

Figure 10. The percentage of respondents from Autos sector on the areas of 'High Investment' in their company, and, 'High Impact' of the performer in five years and thirty years by technologies/trends.

Note: Autos industry capital expenditure Towards Energy Efficiency over the Internet of things and smart mobiles

In this survey (Figure 11), fifty-nine per cent of respondents agreed that attention to Cybersecurity is a significant item, for Energy Efficiency and Personalisation of Services. Amongst our respondents who said that in their sector Capital Expenditure flows into Cybersecurity is a significant item were Financial Services (eighty-six per cent) Technology (seventy-six per cent) Utilities (seventy-five per cent) and Pharmaceuticals (seventy per cent). It is maybe reflective of the responses in a related question on Cybersecurity where nearly sixty-five per cent of respondents said that they believe their industries to be 'Well Prepared' to deal with Cybersecurity concerns. 


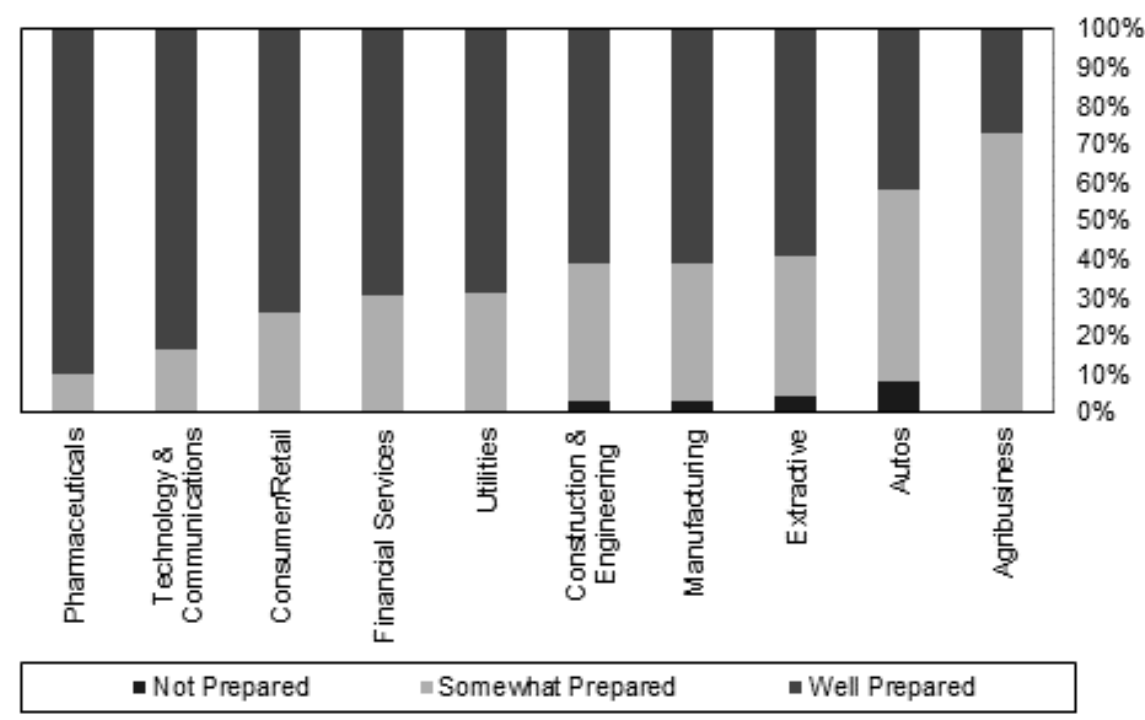

Figure 11. The per cent of respondents, how well prepared their industry is to cooperate with cybersecurity issues?

Note: Utilities how well is your industry prepared to cooperate with cybersecurity issues?

The Cybersecurity assumed to be as a fundamental feature of the next thirty years as the assumption of the digital economy will be supported by the trust that enough Cybersecurity defences are being put in place. The responses have proved a great result on High readiness. Furthermore, it's remarkable that eighty-four per cent of respondents of Technology \& Communications emphasis that their industry is 'Well Prepared' and Pharmaceuticals sector with ninety per cent of respondents mentioned their opinion is well prepared. So the most of the respondents in Utilities (sixty-nine per cent) Consumer \& Retail (seventy-four per cent) and Financial Services (seventy per cent) agrees that their industries are well prepared to deal with Cybersecurity issues. Hence, this result has been taken, which proves a remarkable level of complacency. The more connection is integrated into various sectors, the rate of readiness on Cybersecurity will be enhanced. In this case, the majority of respondents agrees that the Internet of things will be the major tendency for the sectors in the next years; it takes time to ensure enough cyber protection defences. Nevertheless, eighty-two per cent of respondents believe that 'Innovation and Tech' run the changes in competitive landscapes and the majority of responses mentioned tendency in technology will be the major performer in their operating area in next years. 


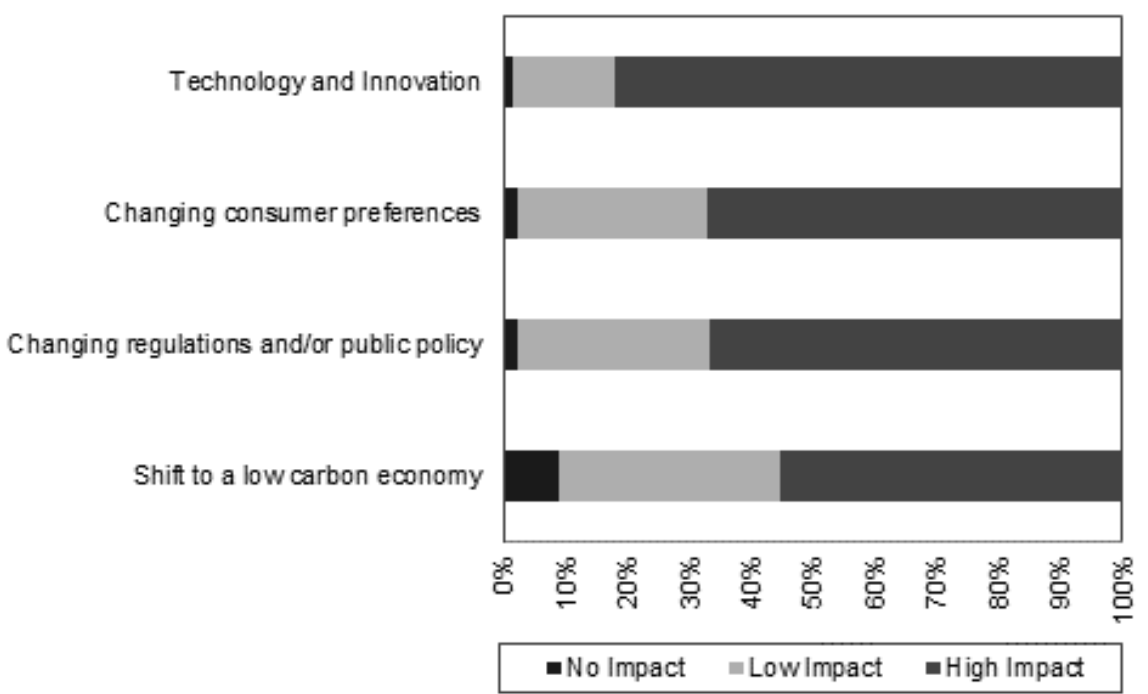

Figure 12. The percentage of respondents on what is run in the change in their industry's competitive

Note: what is run in the change in your industry's competitive landscape?

The result shows (Figure 12) that ninety-five per cent of respondents in Technology and ninety per cent of respondents in Pharmaceuticals mentioned that 'Technology and Innovation' as a major performer in run the change. In the case of the Pharmaceuticals sector, personalisation assumed as the major tendency which will define the industry in the next thirty years. But it will be supported by the increasing junction and telecare. Hence it will be predictable that technology is assumed to be as a major performer in run the change in the competitive landscape. It is also interesting that divergence between the notable answers in the question on Energy Efficiency being the environment most of the respondents mentioned as having a big share of Capital Expenditure, and the relatively more silent answer exists in this part regarding changes to the competitive landscape from the shift to a low carbon economy.

\section{Limitations}

The fast changes in the business environment observed from participants throughout this survey. Customer needs can influence an uncertain business environment, as well. Hence, industries must be careful about customer preferences seriously and adapt themselves with their needs and want continually. The fast change in the technological environment is one of the critical limitation in this research as well. Moreover, the findings of this study are also limited and need to be considered. Essentially, the results have demonstrated only one aspect of the relationship between technologies, IoT development. 


\section{Concluding remarks}

The results prove that the Internet of Things (IoT) will have the most considerable influence across sectors a in the short term and long term both. Seventy-two per cent accept IoT applications will be the leading player in there in the next five years, and it increases to eighty per cent over a 30 year. 3D printing has the lowest influence on their industry. According to the respondent, Innovation is the most impactful in the industries, technology as well. Pay attention to the 'low carbon' as well as consumers preferences are the most disruptors during the next thirty years. It is a contrast between IoT, Automation and Energy Efficiency and Personalisation of Services. 72\% of respondents accept that the internet of things will be the most impactful player in their industries in the next five years and this increases to $80 \%$ in thirty years.

\section{Implications}

In order to conduct 'market research' is one of the essential activities for all industries to find the trend of OIT in future. Thus, Being customer-oriented must be considered as well. Be aware of what competitors are doing (the competitor's orientation). Moreover, the market-oriented (intelligence generation, intelligence dissemination, responsiveness), and flexible responses to market changes are also recommended. The author believes that a better understanding of additional ICT features (i.e. broadband, bandwidth, etc.) related to technology improvements are a vital element in the success of government policies to enhance productivity performance of manufacturing industries, and not only in the case of emerging markets. Further research analysis in this cross-country approach could be worth undertaking.

\section{References}

[1] Patel, S, M Patel, Internet of Things-IoT: Definition, Characteristics, Architecture, Enabling Technologies, Application \& Future Challenges, International Journal of Engineering Science and Computing, pp. 6123-6131, 2016

[2] Vermesan, P. Fries, Internet of Things: Converging Technologies for Smart Environments and Integrated Ecosystems, River Publisher, 2013.

[3] Vermesan, P. Fries, Internet of Things-From Research and Innovation to Market Deployment, River Publisher, 2014.

[4] Adao, R.; Costinot, A.; Donaldson, D. Nonparametric Counterfactual Predictions in Neoclassical Models of International Trade. Am. Econ. Rev. 2017, 107, 633-689.

[5] Nagy, J.; Oláh, J.; Erdei, E.; Máté, D.; Popp, J. The Role and Impact of Industry 4.0 and the Internet of Things on the Business Strategy of the Value Chain-The Case of Hungary. Sustainability 2018, 10, 3491. 
[6] Meyer, N.; Meyer, D.F. The Relationship Between the Creation of an Enabling Environment and Economic Development: a Comparative Analysis of Management At Local Government Sphere. Polish J. Manag. Stud. 2016, 14, 150-160.

[7] Máté, D. Human capital, unions and productivity in a labour-skilled sectoral approach. Soc. Econ. 2014, 36.

[8] Máté, D. Can intellectual property rights impact directly on productivity: a case study in manufacturing industries. Vezetéstudomány 2015, 45, 25-32.

[9] Máté, D.; Oláh, J.; Lakner, Z.; Popp, J. Food chemistry patents influence on productivity: A case study of a sectoral approach in various OECD countries. Polish J. Manag. Stud. 2017, 16.

[10] Postelnicu, C.; Dabija, D.-C. Transfer and Diffusion of New Technologies Within the Supply Chain of Multinational Companies with Operations in Romania-A Contemporary Approach. In Geopolitics, Development, and National Security - Romania and Moldova at the Crossroads; Springer, Cham, 2015; pp. 53-66.

[11] IDC Forecasts, Worldwide Spending on the Internet of Things to Reach $\$ 772$ Billion in 2018, International Data Corporation (IDC), 7. December, 2017.

[12] 5G-The future of IoT, America's white paper, pp. 122, 2019

[13] Oláh, J.; Karmazin, G.; Máté, D.; Grabara, J.K.; Popp, J. The effect of acquisition moves on income, pre-tax profits and future strategy of logistics firms. J. Int. Stud. 2017, 10.

[14] Brailsford, T., Yeoh, D. (2004). Agency Problems and Capital Expenditure Announcements. The Journal of Business, 77(2), 223-256. doi:10.1086/381274 